\title{
Corrigendum: Molecular Cloning, Characterization, and Anti-avian Pathogenic Escherichia coli Innate Immune Response of the Cherry Valley Duck CIITA Gene
}

\begin{abstract}
Rong $\mathrm{Li}^{1,2,3,4 \dagger}$, Mengjiao Guo ${ }^{1,2,34}$, Jing Lin ${ }^{1,2,3,4}$, Tongjie Chai ${ }^{1,3,4 *}$ and Liangmeng Wei ${ }^{1,2,3,4 *}$
\end{abstract}

\begin{abstract}
${ }^{1}$ Sino-German Cooperative Research Centre for Zoonosis of Animal Origin of Shandong Province, College of Veterinary Medicine, Shandong Agricultural University, Tai'an, China, ${ }^{2}$ Collaborative Innovation Center for the Origin and Control of Emerging Infectious Diseases, Taishan Medical University, Tai'an, China, ${ }^{3}$ Shandong Provincial Key Laboratory of Animal Biotechnology and Disease Control and Prevention, Shandong Agricultural University, Tai'an, China, ${ }^{4}$ Shandong Provincial Engineering Technology Research Center of Animal Disease Control and Prevention, Shandong Agricultural University, Tai'an, China
\end{abstract}

Keywords: Cherry Valley duck, CIITA, sequence analysis, receptor expression, inflammatory cytokines, antibacterial ability, innate immunity

\section{OPEN ACCESS}

Edited and reviewed by: Juarez Antonio Simões Quaresma, Universidade Federal do Pará, Brazil

${ }^{*}$ Correspondence: Tongjie Chai chaitj117@163.com

Liangmeng Wei

Imwei@sdau.edu.cn

${ }^{\dagger}$ These authors have contributed equally to this work.

Specialty section: This article was submitted to

Microbial Immunology, a section of the journal

Frontiers in Microbiology

Received: 15 September 2017 Accepted: 23 October 2017 Published: 31 October 2017

Citation:

Li R, Guo M, Lin J, Chai T and Wei L (2017) Corrigendum: Molecular Cloning, Characterization, and Anti-avian Pathogenic Escherichia coli Innate Immune Response of the Cherry Valley Duck CIITA Gene. Front. Microbiol. 8:2172. doi: 10.3389/fmicb.2017.02172

\section{A corrigendum on}

Molecular Cloning, Characterization, and Anti-avian Pathogenic Escherichia coli Innate Immune Response of the Cherry Valley Duck CIITA Gene

by Li, R., Guo, M., Lin, J., Chai, T., and Wei, L. (2017). Front. Microbiol. 8:1629. doi: 10.3389/fmicb. 2017.01629

In the original article Accolla et al. $(1985,1986)$ were not cited in the article. In addition, we erroneously stated the years in which CIITA was discovered; it should have been 1985-1986. The citation and correct date have been inserted in introduction, second paragraph.

The corrected paragraph should read:

In mammals, NLRs are able to recognize bacterial flagella, lipopolysaccharide, RNA, and muramyl dipeptides in the cytoplasm (Franchi et al., 2009). NLRs can be divided into five subfamilies according to the difference in the N-terminal effector domain (Ting and Davis, 2005). Class II major histocompatibility complex (MHC-II) transactivator (CIITA), discovered in 1985-1986 (Accolla et al., 1985, 1986), and contains an acidic transcriptional activation motif in the N-terminal domain, so it belongs to the NLRA subfamily. CIITA plays an important role in the MHC-II transcriptional activation and is positively correlated with the MHC-II transcription level (Muhlethaler-Mottet et al., 1997; Zuo and Rowe, 2012). In addition, CIITA can regulate the presentation function of antigen presentation cells by controlling the transcription level of MHC-II (van den Elsen et al., 2004; Lupfer and Kanneganti, 2012). However, CIITA does not directly bind to DNA but rather acts as a transcriptional co-activator through the activation of transcription factors (Sisk et al., 2003). In addition, CIITA can trans-activate the expression of MHC-II in antigen presentation cells and virus-infected target cells, inducing host-derived antiviral responses, thereby inhibiting the viral replication in the host and eliminating virus infection (Tosi et al., 2011).

The authors apologize for this error and state that this does not change the scientific conclusions of the article in any way. 


\section{REFERENCES}

Accolla, R. S., Jotterandbellomo, M., Scarpellino, L., Maffei, A., Carra, G., and Guardiola, J. (1986). aIr-1, a newly found locus on mouse chromosome 16 encoding a trans-acting activator factor for MHC class II gene expression. J. Exp. Med. 164, 369-374.

Accolla, R. S., Scarpellino, L., Carra, G., and Guardiola, J. (1985). Transacting element(s) operating across species barriers positively regulate expression of major histocompatibility complex class II genes. J. Exp. Med. $162: 1117$.

Franchi, L., Warner, N., Viani, K., and Nuñez, G. (2009). Function of Nod-like receptors in microbial recognition and host defense. Immunol. Rev. 227, 106-128. doi: 10.1111/j.1600-065X.2008. 00734.x

Lupfer, C. R., and Kanneganti, T.-D. (2012). The role of inflammasome modulation in virulence. Virulence 3, 262-270. doi: 10.4161/viru. 20266

Muhlethaler-Mottet, A., Otten, L. A., Steimle, V., and Mach, B. (1997). Expression of MHC class II molecules in different cellular and functional compartments is controlled by differential usage of multiple promoters of the transactivator CIITA. EMBO J. 16, 2851-2860. doi: 10.1093/emboj/16. 10.2851

Sisk, T. J., Nickerson, K., Kwok, R. P., and Chang, C. H. (2003). Phosphorylation of class II transactivator regulates its interaction ability and transactivation function. Int. Immunol. 15, 1195-1205. doi: 10.1093/intimm/dxg116
Ting, J. P., and Davis, B. K. (2005). CATERPILLER: a novel gene family important in immunity, cell death, and diseases. Annu. Rev. Immunol. 23, 387-414. doi: 10.1146/annurev.immunol.23.021704.115616

Tosi, G., Forlani, G., Andresen, V., Turci, M., Bertazzoni, U., Franchini, G., et al. (2011). Major histocompatibility complex class II transactivator CIITA is a viral restriction factor that targets human T-cell lymphotropic virus type 1 Tax-1 function and inhibits viral replication. J. Virol. 85, 10719-10729. doi: 10.1128/JVI.00813-11

van den Elsen, P. J., Holling, T. M., Kuipers, H. F., and Van Der Stoep, N. (2004). Transcriptional regulation of antigen presentation. Curr. Opin. Immunol. 16, 67-75. doi: 10.1016/j.coi.2003.11.015

Zuo, J., and Rowe, M. (2012). Herpesviruses placating the unwilling host: manipulation of the MHC class II antigen presentation pathway. Viruses 4, 1335-1353. doi: 10.3390/v4081335

Conflict of Interest Statement: The authors declare that the research was conducted in the absence of any commercial or financial relationships that could be construed as a potential conflict of interest.

Copyright (c) $2017 \mathrm{Li}, \mathrm{Guo}$, Lin, Chai and Wei. This is an open-access article distributed under the terms of the Creative Commons Attribution License (CC BY). The use, distribution or reproduction in other forums is permitted, provided the original author(s) or licensor are credited and that the original publication in this journal is cited, in accordance with accepted academic practice. No use, distribution or reproduction is permitted which does not comply with these terms. 